\title{
Environmental Inequality, Adverse Birth Outcomes, and Exposure to Ambient Air Pollution in Allegheny County, PA, USA
}

\author{
LuAnn L. Brink • Stacey M. Benson • Lynne P. Marshall • \\ Evelyn O. Talbott
}

Received: 31 January 2014 / Revised: 27 March 2014 / Accepted: 16 April 2014 / Published online: 13 May 2014

(C) W. Montague Cobb-NMA Health Institute 2014

\begin{abstract}
To evaluate how disparities in the distribution of environmental air pollution impact birth outcomes in Allegheny County, PA, we utilized the National Air Toxics Assessment modeled air pollution at the census tract level to evaluate pollution levels and census estimated median income for all census tracts throughout the county. The distribution of air pollution and its contribution to adverse birth outcomes were assessed with concentration curves and multivariable logistic regression models. We determined that benzene, diesel particulate matter, and trichloroethylene levels are significantly higher in census tracts with the lowest median income levels $(p<0.01)$. In addition, for every $1 \mu \mathrm{g} / \mathrm{m} 3$ increase in diesel particulate matter, the odds of a low birth weight outcome increase $14 \%$ $(p=0.024)$ and the odds of a preterm birth increase $16 \%(p=$ $0.004)$. There may be ongoing environmental justice issues wherein poor pregnancy outcomes among the less affluent and minority residents of Allegheny County, PA, may be partially attributed to higher pollution levels in those neighborhoods.
\end{abstract}

Keywords Air pollution · Birth outcomes · Epidemiology · Poverty

\section{Introduction}

Allegheny County (AC) is home to Pittsburgh, PA, with a population of 1.2 million, and has the fifth highest annual $\mathrm{PM}_{2.5}$ levels in the nation. Allegheny County ranks 90th in the

L. L. Brink $(\bowtie) \cdot$ S. M. Benson • E. O. Talbott

Department of Epidemiology, University of Pittsburgh Graduate

School of Public Health, Pittsburgh, PA, USA

e-mail: 1lb38@pitt.edu

L. P. Marshall

Division of Air Quality, Allegheny County Health Department, Pittsburgh, PA, USA nation for the highest benzene concentrations (of 3,275 counties). It is in the top $15 \%$ for trichloroethylene (TCE) concentration (448th of 3,275), in the top $10 \%$ for diesel particulate matter (DPM) concentration (190 of 3,275). Specific components of air pollution have been associated with adverse pregnancy outcomes. Both sulfur dioxide and ambient benzene exposures have been linked to poor birth outcomes. Maternal exposure to ambient benzene levels has been linked to neural tube defects [1]. Exposure to benzene and nitrogen dioxide is linked to preterm births [2], while mothers exposed to the highest levels of sulfur dioxide had 2.88 times higher odds of giving birth to a very low birth weight infant $(<1,500 \mathrm{~g})$ than those exposed to the lowest levels [3]. In many of these studies, models were adjusted for race, age, sex, and socioeconomic status (SES), and the results remained significant. Recently, coarse and fine particulate matter $\left(\mathrm{PM}_{10}\right.$ and $\mathrm{PM}_{2.5}$ ) has been associated with low birth weight internationally [4-7] and in Allegheny County, PA [8, 9].

Benzene may affect birth weight by causing oxidative damage in cells and suppressing cell growth [10-12]. It has also been associated with decreased intrauterine growth [13]. A national assessment of maternal exposure to benzene, as modeled by NATA in 1996 and 1999, found an increase in the odds of a low birth weight (LBW) event. They also found that birth weight of newborns significantly decreased by $16.5 \mathrm{~g}$ for every $1 \mu \mathrm{g} / \mathrm{m}^{3}$ increase in ambient benzene after controlling for personal risk factors [14].

Diesel exhaust has been found to be an endocrinedisrupting chemical that may also affect birth weight [15]. California mothers living in close proximity to high density traffic locations were found to be at increased risk of both preterm births and of term LBW [16]. Traffic density may be a proxy for exposure to fine particles, carbon monoxide, and/or diesel particulate matter. This association was consistent after controlling for personal risk factors, and was strongest in the winter when pollution dispersion is limited. 
An industrial spill of tetrachloroethylene (TCE) served as the exposure of interest in a study of perinatal outcomes among women in New York State living within a TCEcontaminated area. TCE in drinking water had previously been associated with congenital anomalies [17-19]. Women in the study area were found to have significantly elevated rates of LBW $(1.36,95 \% \mathrm{CI}, 1.07-1.73)$ and term LBW infants $(1.68,95 \% \mathrm{CI}, 1.20-2.34)$ [20].

$\mathrm{AC}$ is home to a diverse urban population, with $13.2 \%$ of the people being African-American. However, $28 \%$ of this minority group between 18 and 64 years of age lived in poverty in 2008. This is the highest rate among major metropolitan areas. Pittsburgh also has the highest rate $(62 \%)$ of poverty among African-American children under the age of 5 . Eighty percent of African-American babies born in AC are born to single mothers. This figure is startlingly higher than the national levels of $68 \%$ for African-American babies and $36 \%$ for all babies [21]. Current (2007-2010 aggregate) rate of LBW in Allegheny County is $8.00 \%$, while preterm delivery rate is $12.70 \%$. In the USA and Northeast USA, the rate of LBW is 8.14 and $8.08 \%$, respectively. The preterm rates are 12.0 and $11.2 \%$ for the USA and the Northeast USA. Among the African-American population in AC, these rates are $16.5 \%$ among those unmarried, and $11.1 \%$ among married African-Americans. The white population of AC have rates of $9.9 \%$ among those not married and $5.7 \%$ among those who are married [22].

There are multiple factors that contribute to health outcomes in relation to environmental exposures. Environmental and health disparities exist in the population. The goal of this study was to assess the impact of maternal exposure to DPM, benzene, and TCE in Allegheny County, PA, on adverse birth outcomes and to assess the distribution of environmental pollution and median income across the county at the census tract level.

\section{Methods}

Exposure and Outcome Variables

\section{National Air Toxics Assessment (NATA) Data}

Pollution concentrations were determined from the modeled data provided by the NATA for 2005 . The assessment provides estimates of the concentrations, exposures, and broad estimates of the risk from breathing air toxics. The 2005 NATA estimated 177 of the 187 air toxics. The NATA assessment involves compiling a national air toxic emissions inventory of outdoor stationary and mobile sources. These sources include major stationary sources, e.g., large waste incinerators and factories; area and other sources, e.g., dry cleaners, small manufacturers, and wildfires; and both on road and non-road mobile sources, e.g., cars, trucks, planes, and boats.

We used modeled ambient concentrations of the hazardous air pollutants (HAPs) of interest as estimated at the census tract level within Allegheny County $(n=416)$. NATA estimates were downloaded from the EPA website [23]. The air toxic levels of interest for adverse birth outcomes included benzene, DPM, and TCE.

\section{Median Income Data}

The median household income for each census tract was downloaded from the US Census American Fact Finder website [24]. The table used was the 2009 B25119 American Community Survey. The median income per census tract is a 5 -year average of surveyed data.

\section{Birth Records}

All 2005 births records for Allegheny County, Pennsylvania, were obtained from the Pennsylvania Department of Health $(n=12,995)$. Live births less than $500 \mathrm{~g}$ were excluded from analysis. Birth records include birth weight, gestation, and personal risk factors for the mother. These included maternal age, education, previous pregnancy outcomes, initiation of prenatal care, and whether they were eligible to use WIC assistance. The outcome LBW was categorized as births $<2,500 \mathrm{~g}$. The outcome preterm was births $<37$ weeks gestation, and term LBW was coded as gestational age $\geq 37$ weeks with a birth weight $<2,500 \mathrm{~g}$. Geospatial coordinates were used to link mother's residence to the appropriate census tract using ArcGIS 10.1 mapping software. This final step ensured that each mother received the appropriate census level data for air pollution and median income data.

\section{Statistical Analyses}

\section{Concentration Curves}

Concentration curves allow for the visual and statistical representation of inequality experienced by the population of interest. Any concentration curve that falls on the line of equality means there is no disparity in concentration levels and median income. If the curve falls below the line there is a disproportionately higher concentration of a given pollution within census tracts of higher median income. When the curve falls above the line, it indicates that disproportionately higher levels of pollution were found within lower median income census tracts. Concentration indices are used to quantify the curves themselves. The index can range from -1 to 1 with 0 indicating no disparity, -1 indicating perfect disparity for the poor, and 1 indicating perfect disparity disproportionately affecting the wealthy [25]. Concentration curves were 
generated with the World Bank ADePT software version 5.4. The ADePT package runs in conjunction with Stata of which the Stata C 12 version was used. Continuous values of concentration levels and median income were broken into quintiles with ADePT, and concentration curves with standard errors were generated.

\section{Logistic Regression}

Univariate logistic regression models were run using each pollutant individually as a predictor of each outcome. Any pollutant that showed a positive statistically significant association with a birth outcome was investigated further by adding appropriate covariates as found in the literature. If a covariate was found to be significantly associated with one birth outcome in the univariate analysis, it was included in the multivariable logistic regression equation that was used in assessing all birth outcomes. Mother's race and educational level were entered into the model as categorical variables. Prenatal care, smoking status, gestational diabetes, gestational hypertension, previous poor birth outcomes, and poverty (measured as WIC assistance) were entered into the model as dichotomous variables. Mother's age and plurality were entered into the model as continuous variables. All statistical analyses were performed using Stata/ SE 13.1.

\section{Results}

There were 873 babies born at LBW (8.0\%). Just over $11 \%$ were preterm, and $2.2 \%$ were term LBW. Benzene-estimated exposure was higher for LBW, preterm, and term LBW. DPM concentrations were higher among those with LBW and preterm, but did not appear to be higher among those with term LBW. TCE concentrations were higher among cases of all three adverse birth outcomes. Additional differences were noted. Among those with and without LBW, mothers' age, race, smoking status, WIC eligibility, history of poor birth outcomes, prenatal care, rates of gestational hypertension and singleton births, and educational attainment differed. Among mothers with a preterm delivery, mothers' age did not differ, but the previously noted risk factors and rates of gestational diabetes were different between those born preterm and those at typical gestation. Finally, when comparing mothers who had a child at term LBW to those at typical gestation, mothers

Table 1 Frequencies of exposure variables and covariates by each adverse birth outcome of interest

\begin{tabular}{|c|c|c|c|c|c|c|c|c|c|}
\hline & \multicolumn{9}{|c|}{ Adverse birth outcome } \\
\hline & \multicolumn{3}{|l|}{ LBW } & \multicolumn{3}{|l|}{ Preterm } & \multicolumn{3}{|l|}{ Term LBW } \\
\hline & \multicolumn{3}{|l|}{$(<2,500 \mathrm{~g})$} & \multicolumn{3}{|l|}{ (<37 weeks) } & \multicolumn{3}{|c|}{$(<2,500 \mathrm{~g}$ and $\geq 37$ weeks $)$} \\
\hline & $\begin{array}{l}\text { Yes } \\
(n=873)\end{array}$ & $\begin{array}{l}\text { No } \\
(n=10,006)\end{array}$ & $p$ value & $\begin{array}{l}\text { Yes } \\
(n=1,195)\end{array}$ & $\begin{array}{l}\text { No } \\
(n=9,432)\end{array}$ & $p$ value & $\begin{array}{l}\text { Yes } \\
(n=228)\end{array}$ & $\begin{array}{l}\text { No } \\
(n=10,368)\end{array}$ & $p$ value \\
\hline $\begin{array}{l}\text { Mean (SD) benzene concentration } \\
\mu \mathrm{g} / \mathrm{m} 3\end{array}$ & $1.354(.253)$ & $1.301(.248)$ & $<0.001$ & $1.319(.248)$ & $1.304(.250)$ & 0.05 & $1.349(.246)$ & $1.304(.249)$ & 0.01 \\
\hline $\begin{array}{l}\text { Mean (SD) DPM concentration } \mu \mathrm{g} / \\
\text { m3 }\end{array}$ & $0.822(.689)$ & $0.712(.558)$ & $<0.001$ & $0.795(.730)$ & $0.712(.547)$ & $<0.0001$ & $0.788(.653)$ & $0.720(.570)$ & 0.08 \\
\hline $\begin{array}{l}\text { Mean (SD) TCE concentration } \mu \mathrm{g} / \\
\mathrm{m} 3\end{array}$ & $0.873(.228)$ & $0.837(.195)$ & $<0.001$ & $0.857(.221)$ & $0.838(.196)$ & 0.002 & $0.867(.206)$ & $0.840(.198)$ & 0.04 \\
\hline $\begin{array}{l}\text { Number }(\%) \text { of mothers who have } \\
\text { attained (at least) high school } \\
\text { graduation or GED }\end{array}$ & $751(86.6)$ & $9,173(92.1)$ & $<0.001$ & $1,041(88.7)$ & $8,648(92.1)$ & $<0.001$ & $190(83.7)$ & $9,483(91.9)$ & $<0.001$ \\
\hline Mother's age mean (SD) & $28.4(6.6)$ & $29.0(6.1)$ & 0.004 & $28.7(6.5)$ & $29.0(6.1)$ & 0.11 & $28.2(6.6)$ & $29.0(6.1)$ & 0.04 \\
\hline Number $(\%)$ of white mothers & $540(62.0)$ & $7,721(77.4)$ & $<0.001$ & $799(67.0)$ & $7,271(77.4)$ & $<0.001$ & $136(59.6)$ & $7,921(76.7)$ & $<0.001$ \\
\hline $\begin{array}{l}\text { Number }(\%) \text { of mothers who had } \\
\text { prenatal care }\end{array}$ & $787(96.9)$ & $9,550(99.3)$ & $<0.001$ & $1,064(97.1)$ & $9,033(99.5)$ & $<0.0001$ & $215(98.6)$ & $9,866(99.3)$ & 0.27 \\
\hline Number $(\%)$ of singleton births & $682(78.1)$ & $9,831(98.3)$ & $<0.001$ & $966(80.8)$ & 9,301 (98.6) & $<0.001$ & $206(90.4)$ & $10,036(96.8)$ & $<0.001$ \\
\hline Number (\%) of smoking mothers & $287(33.6)$ & $2,038(20.5)$ & $<0.001$ & $318(27.2)$ & $1,943(20.8)$ & $<0.001$ & $85(38.5)$ & $2,170(21.1)$ & $<0.001$ \\
\hline $\begin{array}{l}\text { Number (\%) of mothers with } \\
\text { gestational diabetes }\end{array}$ & $25(2.9)$ & $313(3.1)$ & 0.67 & $55(4.6)$ & $279(3.0)$ & 0.002 & $4(1.8)$ & $330(3.2)$ & 0.22 \\
\hline $\begin{array}{l}\text { Number }(\%) \text { of mothers with } \\
\text { gestational hypertension }\end{array}$ & $113(12.9)$ & $438(4.4)$ & $<0.001$ & $157(13.1)$ & $405(4.3)$ & $<0.001$ & $27(11.8)$ & $534(5.2)$ & $<0.001$ \\
\hline $\begin{array}{l}\text { Number (\%) of mothers in poverty } \\
\text { (with WIC eligibility) }\end{array}$ & $327(37.9)$ & $2,895(29.2)$ & $<0.001$ & $401(34.2)$ & $2,746(29.4)$ & 0.001 & $99(44.2)$ & $3,042(29.6)$ & $<0.001$ \\
\hline $\begin{array}{l}\text { Number }(\%) \text { of mothers with } \\
\text { previous poor birth outcomes }\end{array}$ & $57(6.5)$ & $333(3.3)$ & $<0.001$ & $80(6.7)$ & $312(3.3)$ & $<0.001$ & $9(0.9)$ & 378 (3.6) & 0.81 \\
\hline
\end{tabular}




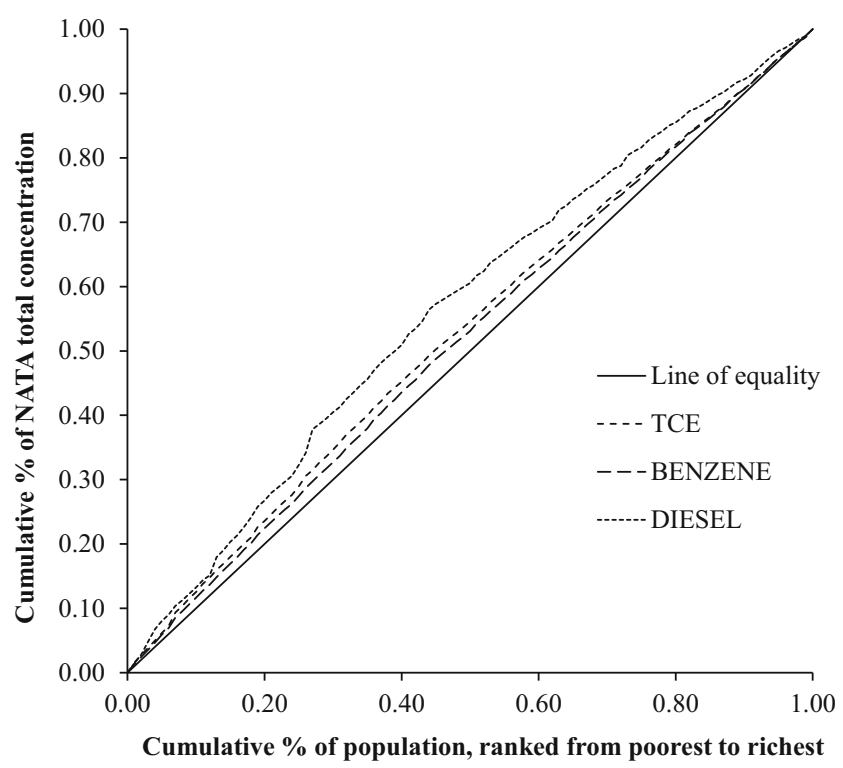

Fig. 1 Concentration curves for DPM, benzene and TCE concentrations, and median income levels across the census tracts of Allegheny County, Pennsylvania

who gave birth to term LBW children were less likely to have received their GED or equivalent, were less likely to be white, had fewer singleton births, were more likely to smoke, were more likely to experience gestational hypertension, and a higher proportion were eligible for WIC (Table 1).

\section{Concentration Curves}

Figure 1 shows the cumulative percentage of total concentration for each pollutant and cumulative proportion of the population ranked by median income for Allegheny County, Pennsylvania. All concentration curves fall above the line of equality indicating these pollutants of interest show disproportionately higher levels of concentration in lower median income level census tracts (Fig. 1). Diesel was the least evenly distributed pollutant with the lowest concentration index of -0.1377 , followed by TCE $(-0.0628)$ and benzene $(-0.0423)$ (Table 2).

\section{Logistic Regression}

Univariable and multivariable logistic regression were used to assess how estimated concentrations of benzene, DPM, and TCE were associated with low birth weight, preterm birth, and term low birth weight. The univariable analyses showed that each pollutant of interest was significantly associated with low birth weight and preterm birth (Table 3). Additionally, benzene and TCE were significantly associated with term low birth weight. However, only DPM was significantly associated with LBW and preterm births once models were adjusted for covariates of interest (Table 3). For every one-unit increase in DPM, the odds of LBW increased by $14 \%$ ( $95 \% \mathrm{CI}, 2$ and $27 \%$ ). Both benzene and TCE showed similar trends but were borderline significant ( $p=0.055$ and $p=0.074$, respectively). For every one-unit increase in DPM, the odds of preterm birth increased by $16 \%$ (95\%CI, 5 and $28 \%)$. The adjusted models included mother's educational level, age, race, prenatal care, plurality, smoking status, gestational diabetes, gestational hypertension, poverty, and previous poor birth outcomes.

\section{Discussion}

Pollution concentrations were disproportionately higher in those census tracts with lower median income. Finding disproportionate levels across census tracts is consistent with an analysis of California air pollution exposure levels in minority and high-poverty neighborhoods. Houston et al. determined that children living in high-poverty neighborhoods experience traffic density at levels two times higher than the rest of Southern California [26]. An analysis of county levels of air pollution and birth outcomes found that Asian Pacific Islanders, African-Americans, and Asians were exposed to higher pollution levels and were two times more likely to live in the most polluted counties. Hispanic mothers were the most likely to experience high pollution in comparison to white mothers. The authors found a small increase in the risk of preterm delivery in relation to air pollution exposures but did not determine if the race/ethnicity of the mother was associated with an increased risk of preterm birth [27]. The Institute of Medicine [28] has suggested that those with fewer means may be more susceptible to the adverse health effects of environmental hazards, thereby creating "double jeopardy" for disadvantaged subgroups. These subgroups, often African-Americans, are likely to live near sources of pollution $[29,30]$.

In this study, we are relying on NATA concentrations. This is one value estimated every 3 years that is attributed to a census tract to represent an annual average based on the National Emissions Inventory data allowing for potential exposure misclassification. However, the Pittsburgh region has a
Table 2 Census tract level $(n=$ 416) pollutant concentration details as determined with NATA modeled pollution and median income

\begin{tabular}{llll}
\hline & Benzene & Diesel PM & TCE \\
\hline Mean concentration (standard deviation) $\left(\mu \mathrm{g} / \mathrm{m}^{3}\right)$ & $1.3565(0.32)$ & $0.7981(0.70)$ & $0.0880(0.03)$ \\
Range of concentration $\left(\mu \mathrm{g} / \mathrm{m}^{3}\right)$ & $0.916-3.789$ & $0.184-8.298$ & $0.065-0.284$ \\
Standard concentration index (standard error) & $-0.0423(0.01)$ & $-0.1377(0.02)$ & $-0.0628(0.01)$
\end{tabular}


Table 3 The association between air pollution concentrations and adverse birth outcomes ${ }^{\mathrm{a}}$

${ }^{a}$ Benzene and DPM were assessed for each $1 \mu \mathrm{g} / \mathrm{m}^{3}$ change in concentration and TCE was assessed for each $0.1 \mu \mathrm{g} / \mathrm{m}^{3}$ change in concentration

*Univariate analysis

**Adjusted for education of mother, prenatal care, mother's age, plurality, smoking, WIC, gestational diabetes, gestational hypertension, previous poor birth outcome, mother's self-selected race

The bold indicates a significant result

\begin{tabular}{lllll}
\hline Outcome & Odds ratio $(95 \% \mathrm{CI})^{*}$ & $p$ value* & Odds ratio $(95 \% \mathrm{CI})^{* *}$ & $p$ value** \\
\hline LBW $(n=10,879)$ & & $(n=10,188)$ & \\
Benzene & $\mathbf{2 . 0 9}(\mathbf{1 . 6 4}, \mathbf{2 . 6 5})$ & $<\mathbf{0 . 0 0 0 1}$ & $1.34(0.99,1.81)$ & 0.0558 \\
Diesel PM & $\mathbf{1 . 2 8}(\mathbf{1 . 1 7}, \mathbf{1 . 4 1})$ & $<\mathbf{0 . 0 0 0 1}$ & $\mathbf{1 . 1 4}(\mathbf{1 . 0 2}, \mathbf{1 . 2 7})$ & $\mathbf{0 . 0 2 4 2}$ \\
TCE & $\mathbf{2 . 0 2}(\mathbf{1 . 5 4}, \mathbf{2 . 6 4})$ & $<\mathbf{0 . 0 0 0 1}$ & $1.39(0.97,1.99)$ & 0.0761 \\
Preterm $(n=10,627)$ & & & $(n=9,964)$ & \\
Benzene & $\mathbf{1 . 2 6}(\mathbf{1 . 0 0}, \mathbf{1 . 5 9})$ & $\mathbf{0 . 0 4 7 3}$ & $0.90(0.68,1.19)$ & 0.4535 \\
Diesel PM & $\mathbf{1 . 2 3}(\mathbf{1 . 1 3}, \mathbf{1 . 3 4})$ & $<\mathbf{0 . 0 0 0 1}$ & $\mathbf{1 . 1 6}(\mathbf{1 . 0 5}, \mathbf{1 . 2 8})$ & $\mathbf{0 . 0 0 4 2}$ \\
TCE & $\mathbf{1 . 5 0}(\mathbf{1 . 1 5}, \mathbf{1 . 9 5})$ & $\mathbf{0 . 0 0 2 5}$ & $1.10(0.78,1.55)$ & 0.5777 \\
Term LBW $(n=10,596)$ & & & $(n=9,793)$ & \\
Benzene & $\mathbf{1 . 8 3}(\mathbf{1 . 1 7}, \mathbf{2 . 8 7})$ & $\mathbf{0 . 0 0 8 0}$ & $1.24(0.74,2.08)$ & 0.4219 \\
Diesel PM & $1.18(0.98,1.41)$ & 0.0768 & $0.98(0.79,1.22)$ & 0.8645 \\
TCE & $\mathbf{1 . 7 1}(\mathbf{1 . 0 3}, \mathbf{2 . 8 4})$ & $\mathbf{0 . 0 3 9 0}$ & $1.24(0.65,2.38)$ & 0.5128 \\
\hline
\end{tabular}

stable population and the time frame of interest had little to no change in manufacturing volume [31]. Due to this consistency, we expect pollution levels between 2004 and 2005 to be fairly consistent which will minimize potential misclassification bias for women who were exposed and gave birth 2005 compared to those who were exposed in 2004 and gave birth in 2005. In an effort to capture mothers who were exposed in 2005 , but gave birth in 2006, an exploratory analysis using 2005 and 2006 birth data revealed that an additional pollutant, benzene, was associated with LBW. For every $1 \mu \mathrm{g} / \mathrm{m}^{3}$ increase in benzene, the odds of a LBW outcome increases $25 \%, p=0.033(95 \% \mathrm{CI}, 1.02,1.54)$. For every $1 \mu \mathrm{g} / \mathrm{m}^{3}$ increase in diesel particulate matter, the odds of a LBW outcome increase $16 \%, p<0.001$ (95\%CI, 1.07, 1.25). Diesel particulate matter remained significantly associated with increased odds of preterm birth as well, $\mathrm{OR}=1.12, p<0.001$ (95\% CI, 1.04, 1.20). Since term LBW is not significantly associated with any pollutant, regardless of whether the dataset used was 2005 births or the combined 2005 and 2006 births, confounding factors may still be present.

Significant associations were observed between the yearly average diesel particulate air pollutant level and birth outcomes (preterm and LBW). A major limitation of this study is that we were not able to account for any change in residence during the pregnancy. In addition, although the outcome variable was at the individual level, both median income and exposure to hazardous air pollution were at the census tract level. Within an urban area such as Pittsburgh, census tracts are fairly small; within the 730 mile $^{2}$ within Allegheny County, there are over 400 census tracts. Similarly, recent work in Allegheny County suggested that exposure to $\mathrm{PM}_{10}$ during pregnancy was associated with an increased risk of LBW among infants born between 1994 and 2000 to mothers residing in Allegheny County, PA [8]. The impact of particulate and hazardous air pollution exposure on LBW in terms of attributable risk at the population level will be great considering the fact that exposure to air pollution is ubiquitous, and appears to occur disproportionately among the less affluent members of the community. Results indicate that there may be ongoing environmental justice issues wherein poor pregnancy outcomes among the less affluent and minority residents of Allegheny County may be partially attributed to higher pollution levels in those neighborhoods. Further studies are required to elucidate this association and to corroborate the findings of potential public health significance.

Conflict of Interest LuAnn L. Brink, Ph.D., Stacey M. Benson, M.S., Lynne P. Marshall, M.S., and Evelyn O. Talbott, Dr. P.H. declare that they have no conflict of interest.

No animal or human studies were carried out by the authors for this article.

\section{References}

1. Lupo PJ, Symanski E, Waller DK, Chan W, Langlois PH, Canfield MA, et al. Maternal exposure to ambient levels of benzene and neural tube defects among offspring: Texas, 1999-2004. Environ Health Perspect. 2011;119(3):397-402.

2. Llop S, Ballester F, Estarlich M, Esplugues A, Rebagliato M, Iniguez C. Preterm birth and exposure to air pollutants during pregnancy. Environ Res. 2010;10:778-85.

3. Rogers FJ, Thompson SJ, Addy CL, McKeown RE, Cowen DJ, Decoufle P. Association of very low birth weight with exposures to environmental sulfur dioxide and total suspended particulates. Am J Epidemiol. 2000;151(8):602-13.

4. Ballester F, Estarlich M, Iniguez C, Llop S, Ramon R, Esplugues A, et al. Air pollution exposure during pregnancy and reduced birth size: a prospective birth cohort study in Valencia, Spain. Environ Health. 2010;9:6.

5. Chen L, Yang W, Jennison BL, Goodrich A, Omaye ST. Air pollution and birth weight in northern Nevada, 1991-1999. Inhal Toxicol. 2002;14(2):141-57. 
6. Dejmek J, Selevan SG, Benes I, Solansky I, Sram RJ. Fetal growth and maternal exposure to particulate matter during pregnancy. Environ Health Perspect. 1999;107(6):475-80.

7. Dugandzic R, Dodds L, Stieb D, Smith-Doiron M. The association between low level exposures to ambient air pollution and term low birth weight: a retrospective cohort study. Environ Health. 2006;5:3.

8. Xu X, Sharma RK, Talbott EO, Zborowski JV, Rager J, Arena VC, et al. PM10 air pollution exposure during pregnancy and term low birth weight in Allegheny County, PA, 1994-2000. Int Arch Occup Environ Health. 2011;84(3):251-7.

9. Lee PC, Talbott EO, Roberts JM, Catov JM, Sharka RK, Ritz B. Particulate air pollution exposure and C-reactive protein during early pregnancy. Epidemiology. 2011;22(4):524-31.

10. Agency for Toxic Substances and Disease Registry (ATSDR). Toxicological profile for benzene. Atlanta: U.S. Department of Health and Human Services; 2007.

11. Laskin JD, Rao NR, Punjabi CJ, Laskin DL, Synder R. Distinct actions of benzene and its metabolites on nitric oxide production by bone marrow leukocytes. J Leukocyte Biol. 1995;57(3):422-6.

12. Rao NR, Snyder R. Oxidative modifications produced in HL-60 cells on exposure to benzene metabolites. J Appl Toxicol. 2006;15(5): 403-9.

13. Slama R, Thiebaugeorges O, Goua V, Aussel L, Sacco P, Bohet A, et al. Maternal personal exposure to airborne benzene and intrauterine growth. Environ Health Perspect. 2009;117(8):1313-21.

14. Zahran S, Weiler S, Mielke HW, Pena AA. Maternal benzene exposure and low birth weight risk in the United States: a natural experiment in gasoline reformulation. Environ Res. 2012;112:139-46.

15. Takeda K, Tsukue N, Yoshida S. Endocrine-disrupting activity of chemicals in diesel exhaust and diesel exhaust particles. Environ Sci. 2004;11(1):33-45.

16. Wilhelm M, Ritz B. Residential proximity to traffic and adverse birth outcomes in Los Angeles County, California, 1994-1996. Environ Health Perspect. 2003;111:207-16.

17. Bove FJ, Fulcomer MC, Klotz JB, Esmart J, Dufficy EM, Savrin JE. Public drinking water contamination and reproductive outcomes. Am J Epidemiol. 1995;141(9):850-62.

18. Goldberg SJ, Lebowitz MD, Graver EJ, Hicks S. An association of human congenital cardiac malformations and drinking water contaminants. J Am Coll Cardiol. 1990;16(1):155-64.
19. Yauck JS, Malloy ME, Blair K, Simpson PM, McCarver DG. Proximity of residence to trichloroethylene-emitting sites and increased risk of offspring congenital heart defects among older women. Birth Defects Res A Clin Mol Teratol. 2004;70(10):808-14.

20. Forand SP, Lewis-Michl EL, Gomez MI. Adverse birth outcomes and maternal exposure to trichloroethylene and tetrachloroethylene through soil vapor intrusion in New York State. Environ Health Perspect. 2012;120(4):616-21.

21. Shattuck RM, Kreider RM. Social and economic characteristics of currently unmarried women with a recent birth: 2011. American Community Survey Reports. United States Census Bureau. 2013.

22. U.S. Centers for Disease Control and Prevention, CDC wonder http:// wonder.cdc.gov. Accessed 15 Nov 2013.

23. U.S. Environmental Protection Agency. 2011. Technology Transfer Network Air Toxics 2005 National-Scale Air Toxics Assessment. http://www.epa.gov/ttn/atw/nata2005/tables.html. Accessed 10 Oct 2013.

24. U.S. Census Bureau, American Factfinder. http://factfinder2.census. gov/faces/nav/jsf/pages/index.xhtml. Accessed 14 Nov 2013.

25. O'Donnel O, van Doorslaer EV, Wagstaff A, Lindelow M. Analyzing health equity using household survey data: a guide to techniques and their implementation. World Bank - free PDF. 2008.

26. Houston D, Wu J, Ong P, Winer A. Structural disparities of urban traffic in Southern California: implications for vehicle-related air pollution exposure in minority and high-poverty neighborhoods. J Urban Aff. 2004;26(5):565-92.

27. Woodruff TJ, Parker JD, Kyle AD, Schoendorf KC. Disparities in exposure to air pollution during pregnancy. Environ Health Perspect. 2003;111:942-6.

28. Institute of Medicine. Toward environmental justice: research, education and health policy needs. Washington: National Academy Press; 1999.

29. Perlin SA, Sexton K, Wong DW. An examination of race and poverty for populations living near industrial sources of air pollution. J Expo Anal Environ Epidemiol. 1999;9(1):29-48.

30. Perlin SA, Wong D, Sexton K. Residential proximity to industrial sources of air pollution: interrelationships among race, poverty, and age. J Air Waste Manag Assoc. 2001;51(3):406-21.

31. Allegheny County Economic Trends. Deitrick S, Briem C. University of Pittsburgh; 2005. 